\title{
Reducing crashes and injuries among young drivers: what kind of prevention should we be focusing on?
}

\author{
H-Y Berg
}

Injury Prevention 2006;12(Suppl I):i15-i18. doi: 10.1136/ip.2006.012062

Every year, drivers throughout the world are killed or injured in road traffic. Young drivers run a greater risk everywhere, and this problem is still largely unsolved. Better understanding of the underlying processes could, however, be a useful tool in preventive endeavours. To change a young driver's goals behind driving and the context in which it is done, a variety of different methods of persuasion should be tested. Both "soft" and "hard" methods should be used. For example, communication and increased enforcement may be used simultaneously. Communication campaigns should highlight the dangers of unsafe behaviour and in particular target young males. Communication campaigns that employ persuasive, emotional messages are most effective where young drivers are concerned. Research shows

Correspondence to: Dr H-Y Berg, Driver Education Specialist, Vägverket (Swedish' Road Administration), Röda vägen 1,781 87 Borlänge, Sweden; hans-yngve. berg@vv.se

Accepted 27 April 2006 that attitudes about safety are formed at an early age, long before legal driving, and therefore it would also be important to target young adolescents. Laws need enforcement to be effective and should target areas of particular risk to young drivers. Driver education or communication campaigns cannot be expected to radically change a young person's life goals. For that purpose, active learning methods that make use of the learner's own experiences have to be applied. Special courses for young drivers designed to make individuals conscious of their personal tendencies and the type of social context that affects their driving behaviour could be helpful, whether offered via the ordinary school system or at driving schools.

$\mathrm{R}$ oad traffic is the cause of one of the world's greatest public health problems. In 2000, 1.26 million people died as a result of road crashes, representing $25 \%$ of all deaths caused by injuries. The majority of road deaths take place in developing countries, and the economic cost to the developing world amounts to 100 billion US dollars annually-more than the entire amount of money spent on development aid. The significance of traffic as a health problem is rising, especially in developing countries. Worldwide, road traffic injuries are the leading cause of death for people aged 15-44.

When, as in Sweden and many other countries, the ambition is to improve on an already high level of road safety, huge efforts are required. Existing measures have to be further developed, but this is probably not enough. As a result, new methods will have to be devised, especially with regard to young, recently qualified car drivers. The 18-24 year age category is the one with the highest risk of all new drivers. This is largely attributable to lack of experience of car driving and other age related factors. ${ }^{2}$

\section{Age, experience, and crash risk}

Against this background, one important aspect that has been studied is how the age of licensure and the driving experience gained after licensure influence the risk of crashes on the road. An American study attempted to estimate the effects of age and experience, and also of "curfews", as well as compulsory driver training and the minimum age for alcohol consumption. ${ }^{3}$ This study, which was carried out in the USA, showed that age was critical in terms of the level of crash risk, and that 15 year olds in particular were more at risk. According to the results of this study, experience is also significant, but not to the same degree as age. The results also show that the effect of high crash risk due to low driving experience decreases with increasing age. ${ }^{3}$

There are also a large number of studies and reviews that show that experience is more significant than age with regard to crash risk in traffic. ${ }^{4-6}$
The conclusions that can be drawn from the above studies and reviews are that both age correlated causes and experience are significant to the crash risk a driver is exposed to in traffic.

\section{What are the factors affecting the way a driver drives a car?}

The research of recent years in the field of driver training has indicated that a hierarchical approach to the task of driving can help to identify specifically which skills a driver needs to avoid crashes and injuries. The idea behind a hierarchical approach is that success as well as failure on the higher levels will affect the demand on lower levels. ${ }^{7}$ Keskinen divided the task of driving into four separate levels (fig 1), in which the higher levels are considered to always affect behavior on the lower levels, although the lower levels may also affect the higher ones. ${ }^{8}$

\section{Goals for life and skills for living}

The fourth level, Goals for life and skills for living, deals with how a person's various motives and goals for life, in a particular phase of his or her life, affect that person's way of driving. Here, the car is regarded as a means of achieving the different goals for life that a person has set himself or herself. The idea is also that factors such as what we are like as individuals and how we live our day-to-day lives also affect our approach to driving and our behaviour as drivers. These factors also include personality factors such as self-control, as well as lifestyle, social background, gender, age, group affiliation and other preconditions that research has shown to have influence on attitudes, motives, choices, and behaviour as a driver. ${ }^{9-12}$

\section{Goals and context of driving}

The third level, Goals and context of driving, refers to the goals and purpose of the journey and the environment in which it is made. In this context, the car is viewed as a tool for

Abbreviation: GDE, Goals for Driver Education. 


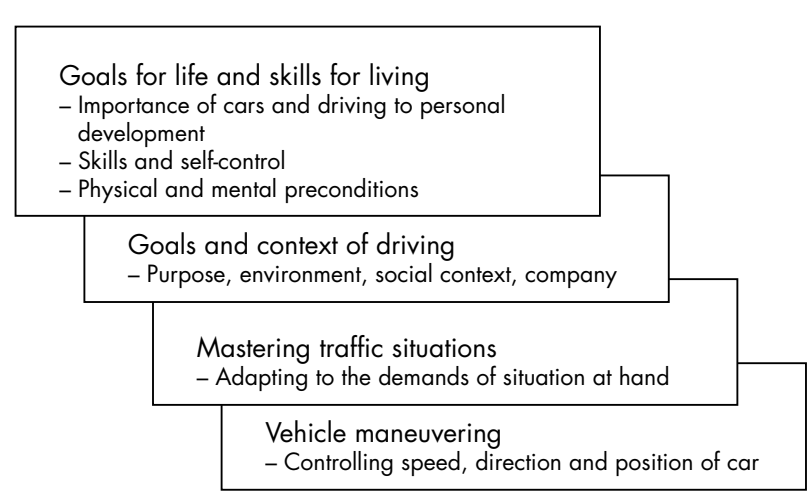

Figure 1 Hierarchical levels of driver behavior (adapted from Keskinen ${ }^{8}$.

meeting the demands of everyday life. On this level, the driver must decide when, with whom, and whether he or she should drive. Such decisions have a major bearing on road safety.

According to Peräaho et al, ${ }^{13}$ this includes, for example, planning a driving route and driving time (for example, daytime or night-time driving), as well as choice of driving state (alcohol, stress, fatigue, etc), and driving company.

\section{Mastery of traffic situations}

The second lowest level, Mastery of traffic situations, is about driving in specific traffic situations. Mastery of many different traffic situations is a vitally important skill for a driver to acquire. A driver must, while driving, interact with other road users, be able to anticipate their behaviour and make it possible for other drivers to understand and anticipate his or her driving behavior. Knowledge of traffic rules, hazard perception, and interaction with other road users are typical tasks at this level.

\section{Vehicle maneuvering}

Vehicle maneuvering is the basis of driving. If a driver has not practiced to the extent that he or she can perform the most fundamental maneuvers automatically, considerable problems arise in managing the huge flow of information that a driver needs to process and decide on while driving. In addition, a driver needs to know about how a car should be equipped and maintained to make it as safe as possible. This level includes not only basic skills such as knowledge of controls, driving off, braking, gear changing, and so on, but also more complex knowledge such as keeping the car under control, evasive maneuvering, understanding the concept of traction, the impact of seat belts, etc.

\section{FROM A STRICTLY HIERARCHICAL MODEL TO A SKILLS BASED MODEL FOR DRIVERS}

In analyzing what a driver needs to know in order to drive safely, it emerges that good maneuvering skills alone are not enough. A driver must also have the will to behave correctly and the experience needed to enable him or her to behave correctly. A driver must also understand that the social context affects what a person can do, wants to do, and is permitted to do as a driver. To be able to drive successfully, every learner must learn what is correct behavior in different situations, what can affect behavior, and how to develop thinking to be able to evaluate him- or herself, driving, and choice of transport in various situations.

A proficiency model comprising Goals for Driver Education (GDE) (table 1) states specifically what driver training should focus on in order to produce the safest possible new drivers. ${ }^{7}$ A study of the model reveals that the tasks of a driver are many: first, any journey has to be planned; then, various choices have to be made to establish the best way of getting to a destination; and furthermore, the driver must be able to handle a car in a large number of different traffic situations, and do so in a way that minimizes risk. All of this must be done in a social context that influences the individual's choices in some direction.

The model is constructed on the four hierarchical levels shown in figure 1. However, it also extends over three columns, Knowledge and skills a driver has to master, Risk-increasing factors a driver must be aware of and Self-evaluation. Knowledge and skills a driver has to master focuses on the theoretical knowledge and skills necessary to drive the car and use it in a way to convey the person to where he or she wants to go. Risk-increasing factors a driver must be aware of focuses on what may affect the risk of crash and injury that is always present during driving. Selfevaluation focuses on the ability of the individual driver to evaluate his/her knowledge and skills accurately. The main principle here is self-evaluation with regard to driving and traveling. The four levels, combined with the three areas of knowledge, lead directly to various driving skills. Together, they identify the proficiency that a driver needs to be able to drive a car safely. Table 1 provides examples of the skills encompassed by the GDE matrix.

\section{FROM SOLELY SPECIFYING DRIVING SKILLS TO DEVELOPING PREVENTIVE MEASURES FOR YOUNG DRIVERS}

The structure of the GDE may be modified from one that specifies only what a driver needs for essential skills, knowledge, and awareness into a tool for developing various different preventive measures aimed at improving safety among young drivers. If the GDE matrix is to be used for this purpose, the preventive measures must be developed by taking into account the background research behind the GDE matrix. The lowest level in the GDE matrix, Vehicle maneuvering, may be said to fall within the operational category of driving, while the second lowest level, Mastery of traffic situations, is classified within the tactical category and the third level, Goals and context of driving, is rather to be attributed to the strategic side of driving. Breaking down the GDE model via a scale ranging from operational to strategic, via tactical, in which the strategic element affects the tactical, which then affects the operational side, makes it possible to develop preventive measures at a higher level than those that merely try to train newly qualified drivers to improve their "car control handling skills". When viewed from this perspective, it is easy to understand why several attempts to improve safety by improving skills on the two lowest levels, Vehicle maneuvering and Mastery of traffic situations, usually show a failure to reduce crashes ${ }^{14}{ }^{15}$ Hatakka et al find that: "if the motivational level fails to produce a safe strategy for driving, no level of skills in mastering traffic situations or vehicle handling is high enough to compensate for this lack of safety orientation and to produce a safe output" (page 15). ${ }^{16}$

The terms age and experience may be said to be two general concepts covering a host of qualities which affect the risk of a crash. Extensive driving experience is important in terms of the capacity to handle the large volume of information received by a driver, and, at the same time, to drive the car. In addition, great experience is a must in automating the task of driving as much as possible, thereby releasing mental resources for interacting with other road users. Age, for its part, more affects how and for what purpose a car is used. If age and experience are to be related to the GDE matrix, it may be said that the two lowest levels, Vehicle maneuvering and Mastery of traffic situations, have more to do with experience, because all drivers irrespective of age must 
Table 1 Goals for Driver Education framework ${ }^{7}$

\begin{tabular}{|c|c|c|c|}
\hline \multirow{2}{*}{$\begin{array}{l}\text { Hierarchical level of } \\
\text { behavior }\end{array}$} & \multicolumn{3}{|l|}{ Essential contents (examples) } \\
\hline & Knowledge and skills & Risk increasing factors & Self-evaluation \\
\hline $\begin{array}{l}\text { Goals for life and skills } \\
\text { for living (general) }\end{array}$ & $\begin{array}{l}\text { Knowledge about/control over how } \\
\text { life goals and personal tendencies } \\
\text { affect driving behavior } \\
\text { lifestyle/life situation } \\
\text { group norms } \\
\text { motives } \\
\text { - self-control, other characteristics } \\
\text { personal values } \\
\text { etc }\end{array}$ & $\begin{array}{l}\text { Risky tendencies } \\
\text { acceptance if risks } \\
\text { self-enhancement through driving } \\
\text { high level of sensation seeking } \\
\text { complying with social pressure } \\
\text { - use of alcohol/drugs } \\
\text { values, attituted towards society }\end{array}$ & $\begin{array}{l}\text { Self-evaluation/awareness of } \\
\text { - personal skills for impulse } \\
\text { control } \\
\text { - risky tendencies } \\
\text { - safety negative motives } \\
\text { - personal risky habits } \\
\text { etc }\end{array}$ \\
\hline $\begin{array}{l}\text { Goals and context of } \\
\text { driving (trip related) }\end{array}$ & $\begin{array}{l}\text { Knowledge and skills concerning } \\
- \text { effects of trip goals on driving } \\
\text { planning and choosing routes } \\
\text { evaluation of social pressure in car } \\
\text { - evaluation of necessity of trip } \\
\text { etc }\end{array}$ & $\begin{array}{l}\text { Risks connected with } \\
\bullet \text { driver's condition (mood, BAC, etc) } \\
\text { purpose of driving } \\
\text { - driving environment (rural/urban) } \\
\text { social context and company } \\
\text { - extra motives (competing etc) } \\
\text { etc }\end{array}$ & $\begin{array}{l}\text { Self-evaluation/awareness of } \\
\text { personal planning skills } \\
\text { typical goals of driving } \\
\text { typical risky driving motives } \\
\text { etc }\end{array}$ \\
\hline Mastery of traffic situations & $\begin{array}{l}\text { Knowledge and skills concerning } \\
\text { traffic rules } \\
\text { observation/selection of signals } \\
\text { anticipation of course of situations } \\
\text { speed adjustment } \\
\text { communication } \\
\text { driving path } \\
\text { driving order } \\
\text { - distance to others/safety margins } \\
\text { etc }\end{array}$ & $\begin{array}{l}\text { Risks caused by } \\
\text { nrong expectations } \\
\text { risk increasing driving style (eg aggressive) } \\
\text { unsuitable speed adjustment } \\
\text { nulnerable road users } \\
\text { information rules/unpredictable behavior } \\
\text { - infficult conditions (darkness etc) } \\
\text { - etc }\end{array}$ & $\begin{array}{l}\text { Self-evaluation/awareness of } \\
\text { - strong and weak points of basic } \\
\text { traffic skills } \\
\text { - personal driving style } \\
\text { - personal safety margins } \\
\text { - strong and weak points for } \\
\text { hazard situations } \\
\text { - realistic self-evaluation } \\
\text { etc }\end{array}$ \\
\hline Vehicle maneuvering & $\begin{array}{l}\text { Knowledge and skills concerning } \\
\text { control of direction and position } \\
\text { tyre grip and friction } \\
\text { vehicle properties } \\
\text { physical phenomena } \\
\text { etc }\end{array}$ & $\begin{array}{l}\text { Risks connected with } \\
\text { Insufficient automatism/skills } \\
\text { Unsuitable spped adjustment } \\
\text { - difficult conditions (low friction etc) } \\
\text { etc }\end{array}$ & $\begin{array}{l}\text { Awareness of } \\
\text { - strong and weak points of basic } \\
\text { maneuvering skills } \\
\text { - strong and weak points of skills } \\
\text { for hazard situations } \\
\text { - realistic self-evaluation } \\
\text { etc }\end{array}$ \\
\hline
\end{tabular}

possess the skills specified in the GDE matrix. The two top levels, Goals for life and skills for living and Goals and context of driving, are more age specific. Against that background, influencing the motivation of the young driver category for driving is more likely to be effective in terms of crash and injury prevention than attempting to make them into even more skilled drivers technically. The focus should therefore be to make young drivers aware that their personal motives, tendencies, and social relations in the broader sense always affect their goals and context of driving, with the aim of getting them to change their goals behind driving and the context in which driving is performed-that is, why a driver is driving on a certain occasion, where and when, and with whom. In this way, by bringing about a change in driving habits through improved planning of driving route and driving time (day or night), as well as choice of driving state (alcohol, stress, fatigue, etc) and driving company, it should be possible to reduce the number of driving related injuries.

\section{Which preventive measures could work?}

To change a young driver's goals behind driving and the context in which it is performed, a wide variety of different methods of persuasion should be tested. Both "soft" and "hard" methods should be used. For example, communication and increased enforcement may be used simultaneously. Communication campaigns should highlight the dangers of unsafe behavior and should particularly target young males, as well as other young drivers, role models, and pre-driving teens. ${ }^{17}$ Long lasting effects of communication campaigns seem difficult to achieve, and therefore we can learn much from successful campaigns and the strategies they use. ${ }^{17}$
Communication campaigns that employ persuasive, emotional messages are the most effective where young drivers are concerned. These should place particular emphasis on issues such as speed, drunk driving, mobile phone use, etc, and should target young males. ${ }^{17}$ Research also shows that attitudes about safety are formed at an early age, long before legal driving, and on that basis it would also be important to target young adolescents. ${ }^{11}$

Laws need enforcement to be effective and should target areas of particular risk to young drivers. ${ }^{17}$ Enforcement and communication campaigns should be used in combination. Combination of different methods gives the best results. ${ }^{17}$

Economic incentives could promote safer behavior and target young males in particular (for example, lower insurance premiums for young drivers who have no incidents or who use certain technology).

It cannot be expected that driver education or communication campaigns will radically change a young person's life goals. For that purpose, active learning methods that make use of the learner's own experiences have to be applied. ${ }^{13}$ Special courses for young drivers designed to make individuals conscious of their personal tendencies and the type of social context that affects their driving behavior could be helpful for this purpose, whether offered via the ordinary school system or at driving schools. The key to learning about the higher levels in the hierarchy and to raising the level of self-evaluative skills lies in the activity of the learner himself or herself. ${ }^{13}$ Training of self-evaluative and meta-cognitive skills must therefore be included in courses for young drivers. This provides an opportunity for developing expertise after training, and for attaining and modifying motives and goals 
on the highest levels of the hierarchy. ${ }^{13}$ This strategy could change a young driver's choices about where, when, and with whom he or she drives a car.

In addition, modern technology is also available for preventive purposes, including protective measures based on technology targeting speed (for example, "black box" devices) and the alco-lock, which prevents drink driving. Smart cards could be used in preventing unauthorized driving.

\section{DISCUSSION}

Every year, drivers throughout the world are killed or injured in road traffic. Young drivers run a greater risk everywhere, and this problem is still largely unsolved. Better understanding of the underlying processes could, however, be a useful tool in preventive endeavors. The focus of this paper is to give an understanding that a person's life ambition (goals for life) and goals and context of driving sometimes influence young drivers and their passangers in terms of traffic safety more than their ability of mastering different driving situations and their skill of vehicle maneuvering. Better knowledge of these factors will make it possible to design safety measures specially tailored for young drivers or different subgroups of drivers. This is expected to help make the measures more effective and to reduce the conflict between mobility and safety.

The idea behind the GDE matrix offers the possibility of developing different countermeasures for young drivers. If this is adapted as closely as possible to this group and their driving situations, it should be possible to significantly enhance safety.

In most countries of the world, young drivers show a high crash risk relative to elderly and more experienced drivers. Examination of the actual figures indicates that only $1-2 \%$ of young drivers (per year) are involved in a fairly severe crash. Against that background, it is important to take the concept of health into consideration, since a healthy life does not consist only of the absence of misfortune. Human health also includes physical and psychological wellbeing. The World Health Organization ${ }^{18}$ defines health as:

1. A state of complete physical, social and mental wellbeing, and not merely the absence of disease or infirmity.

2. Health is a resource for everyday life, not the object of living. It is a positive concept emphasizing social and personal resources, as well as physical capabilities.

Being able to get around by car when and where one wants is a source of wellbeing for many young people. Restricting the needs of the majority because of the few who are involved in a crash risks lowering the collective level of health for young people as a group. Selective influence is therefore important from two viewpoints: eliminating as many crashes as possible, without simultaneously restricting mobility for young people as a whole. If this is done in a way that is properly suited to the target groups and the situation at hand, it should be possible to achieve significant positive effects on safety and health at the same time.

\section{ACKNOWLEDGEMENTS}

This paper was first presented as part of the first Expert Panel meeting of the Youthful Driver Research Initiative, a collaborative research program between the Center for Injury Research and Prevention (http://www.chop.edu/injury) at the Children's Hospital of Philadelphia (CHOP) (http://www.chop.edu) and State Farm Insurance Companies ${ }^{\circledR}$ (State Farm) (http://www.statefarm.com). The views presented in this paper are those of the author(s) and are not necessarily the views of CHOP or State Farm.

\section{About the author}

Hans-Yngve Berg is a Driver Education Expert with The Swedish Road Administration. Dr Berg is working on the development of the Swedish and European driver education system and also manages research projects conducted by universities and other independent research units in the field of behavioral science. Dr Berg also provides information and support to the public, to authorities, and to other people involved in the area of traffic safety. He is a senior lecturer at the Karolinska Institutet in Stockholm, primarily on the topics of traffic safety, driver education, and research methodology. He received his Doctor of Philosophy degree in 2001 (Social Medicine and Public Health Science). He also has a Master of Social Science in Education and a Bachelor of Science in Human Resource Development and Labour Relations. All degrees are from Linköping University, Sweden. The SRA is the national authority assigned the overall sectoral responsibility for the entire road transport system of Sweden.

\section{REFERENCES}

1 Geleta B. Global Road Safety Crisis. Statement delivered by Deputy Head of Delegation, Deputy Permanent Observer to the United Nations, International Federation of Red Cross and Red Crescent Societies representative, at the 58th UN General Assembly in New York. Available at http://www.ifrc.org/docs/ news/speech03/bg221003.asp/ (accessed March 2006).

2 In: Simpson H, ed. New to the road. Reducing the risks for young motorists. University of California, Los Angeles: Youth Enhancement Service, 1996.

3 Levy DT. Youth and traffic safety: The effects of driving age, experience, and education. Accid Anal Prev 1990;22:327-34.

4 Maycock G, Lockwood CR, Lester JF. The accident liability of car drivers. (TRL Research Report 315). Crowthorne, Berkshire, UK: Transport Research Laboratory, 1991.

5 Mayhew DR, Simpson HM. The role of driving experience: implications for the training and licensing of new drivers. Toronto, Ontario: Insurance Bureau of Canada, 1995

6 Gregersen NP. Evaluation of 16-years age limit for driver training-first report, VTI Report 418A. Linköping, Sweden: Swedish Road and Transport Research Institute, 1996.

7 Hatakka M, Keskinen E, Gregersen NP, et al. From control of the vehicle to personal self-control; broadening the perspectives to driver education. Transportation Research Part F 2002;5:201-15.

8 Keskinen E. Why do young drivers have more accidents? Junge Fahrer und Fahrerinnen. Referate der Ersten Interdiziplinären Fachkonferenz, December 12-14, 1994 in Köln. Berichte der Bundesanstalt für Strassenwesen. Mensch und Sicherheit, Heft M 52, 1996

9 Jessor R. Risky driving and problem adolescent behavior: An extension of problem behavior theory. Alcohol Drugs Driving 1987;3:1-11.

10 Schulze H. Lifestyle, leisurestyle and traffic behaviour of young drivers. VTI rapport 364A. Linköping, Sweden: Statens Väg-och transportforskningsinstitut, 1990

11 Berg HY. Lifestyle, traffic and young drivers - an interview study. VTI Report 389A. Linköping, Sweden: Swedish National Road and Transport Research Institute, 1994.

12 Hatakka M. Novice drivers' risk- and self-evaluations. Doctoral thesis. Turku, Finland: University of Turku, Series B, 1998

13 Peräaho M, Keskinen E, Hatakka M. Driver competence in a hiearchical perspective; implications for driver education. Report to Swedish Road Administration, 2003

14 Glad A. Fase 2 i föreroppläringen. Effekt på ulykkes risikoen. Rapport 0015. Oslo, Norway: Transportökonomisk institutt, 1988 [in Norwegian].

15 Christensen P, Glad A. Mandatory course of driving on slippery roads for driver of heavy vehicles. The effect on accidents. TÖl 334/1996. Oslo, Norway: Transportökonomisk institutt, 1996

16 Hatakka M, Keskinen E, Gregersen NP, et al. Theories and Aims of Education and Training Measures. In:Driver Training, Testing and Licensing-towards theory-based management of young drivers' injury risk in road traffic. Results of EU-Project GADGET, Work Package 3. In: Siegrist S (ed). Bfu-Report 40, 1999

17 Engström I, Gregersen NP, Hernetkoski K, et al. Young novice drivers, driver education and training: A literature review. Linköping, Sweden: Swedish National Road and Transport Research Institute, 2003.

18 World Health Organization (WHO). Constitution of the World Health Organization. Available at http://policy.who.int/cgi-bin/om_isapi. dll ?hitsperheading $=$ on\&infobase $=$ basicdoc\&record $=\{C 88\} \&$ softpage $=$ Document42 (accessed April 2006). 